\title{
Increased Adipose and Muscle Insulin Sensitivity Without Changes in Serum Adiponectin in Young Female Collegiate Athletes
}

\author{
Kaori Kitaoka, NRD, PhD, ${ }^{1,2}$ Mika Takeuchi, NRD, PhD, Ayaka Tsuboi, NRD, \\ Satomi Minato, NRD, ${ }^{1,4}$ Miki Kurata, NRD, ${ }^{1,3}$ Shigehiro Tanaka, MD, PhD, \\ Tsutomu Kazumi, MD, PhD, ${ }^{1,6}$ and Keisuke Fukuo, MD, $\mathrm{PhD}^{1,3}$
}

\begin{abstract}
Background: Effects of endurance training on adipose insulin sensitivity in association with body composition, circulating adipokines, and markers of inflammation have been studied less in young Asian subjects.

Methods: Adipose insulin sensitivity/resistance was compared between 170 female Japanese collegiate athletes and 311 nonathletes (18-24 years), who underwent measurements of serum adipokines, markers of insulin sensitivity, inflammation, and dual-energy X-ray absorptiometry. Two separate subsamples of two groups of women underwent either a 75-gram oral glucose tolerance test or a standardized meal test, but not both.

Results: As compared with nonathletes, athletes, characterized by higher skeletal muscle mass and lower percentage of body fat (both $P<0.001$ ), had lower adipose insulin resistance (IR) (a product of fasting insulin and nonesterified fatty acid (NEFA) and lower leptin/adiponectin ratio (both $P<0.001$ ). Although athletes had lower postmeal/postglucose insulinemia ( $P=0.009$ and 0.01 , respectively), the two groups did not differ in postmeal percentage NEFA suppression and postmeal/postglucose glycemia, suggesting increased insulin sensitivity in adipose tissue and skeletal muscle, respectively. Serum leptin $(P<0.001)$ and tumor necrosis factor- $\alpha(P=0.01)$ were lower in athletes, whereas adiponectin and homeostasis model assessment IR did not differ.

Conclusions: Endurance training was associated with increased insulin sensitivity in adipose tissue as well as skeletal muscle without changes in circulating adiponectin even in young, normal-weight Japanese women.
\end{abstract}

Keywords: endurance training, insulin sensitivity, adipose tissue, skeletal muscle, adiponectin

\section{Introduction}

$\mathrm{D}$ ESPITE REMARKABLE ADVANCES in cardiovascular health promotion, cardiovascular disease (CVD) remains the leading cause of death worldwide, with obesity being a rising contributor. ${ }^{1}$ Obesity, an important risk factor for CVD even in Asians, ${ }^{2}$ is associated with chronic low-grade systemic inflammation, in part, because of increase in proinflammatory systemic milieu imposed by proinflammatory cytokines. ${ }^{3}$ Adipocytes are a major source of proinflammatory cytokines and are implicated in the onset and progression of obesity, insulin resistance (IR), and CVD. ${ }^{3,4}$ Proinflammatory adipokines, leptin, interleukin-6, and C-reactive protein, are higher, whereas adiponectin, the main anti-inflammatory and insulinsensitizing compound, is lower in obesity. ${ }^{5,6}$

A recent meta-analysis ${ }^{7}$ has shown that endurance training has favorable effects on most of the cardiovascular risk factors associated with metabolic syndrome, including abdominal obesity, blood pressure, glucose, and dyslipidemia. In addition, a recent systematic review ${ }^{8}$ has revealed that

\footnotetext{
${ }^{1}$ Research Institute for Nutrition Sciences, Mukogawa Women's University, Nishinomiya, Japan.

${ }^{2}$ Department of Welfare and Nutrition, Faculty of Health Welfare, Kansai University of Welfare Sciences, Osaka, Japan.

${ }^{3}$ Department of Food Sciences and Nutrition, School of Human Environmental Sciences, Mukogawa Women's University, Nishinomiya, Japan.

${ }^{4}$ Graduate School of Human Science and Environment, University of Hyogo, Himeji, Japan.

${ }^{5}$ Department of Health and Sports Sciences, Mukogawa Women's University, Nishinomiya, Japan.

${ }^{6}$ Division of Diabetes, Department of Medicine, Kohnan Kakogawa Hospital, Kakogawa, Japan.
}

(C) Kaori Kitaoka et al. 2017; Published by Mary Ann Liebert, Inc. This is an Open Access article distributed under the terms of the Creative Commons Attribution License, which permits unrestricted use, distribution, and reproduction in any medium, provided the original work is properly cited. Mary Ann Liebert, Inc. offers reprint services for those who want to order professionally produced copies of articles published under the Creative Commons Attribution (CC BY) license. To obtain a price quote, email Reprints@liebertpub.com. Please include the article's title or DOI, quantity, and delivery destination in your email. 
physical activity positively affects key players in atherosclerosis development, including $\mathrm{IR}^{9}$ and inflammatory markers. However, the majority of these studies included middle-aged, overweight, and obese subjects, with very few studies including young normal-weight women, or Asian women. In addition, the role of resistance to the antilipolytic effect of insulin has been less investigated, although hepatic and muscular IR has gained much attention and investigation. Furthermore, effects of endurance training on adipose and muscle IR, in association with body composition, serum adipokines, and markers of inflammation, have hardly been investigated in a single study. The present study, therefore, compared adipose insulin sensitivity/resistance cross-sectionally between sedentary and endurance-trained female college students, populations in which confounding factors are so scarce. ${ }^{10-12}$

\section{Materials and Methods}

We studied 170 female collegiate athletes and 311 untrained female students aged 18-24 years, whose details have been reported elsewhere. ${ }^{10-12}$ They were all Japanese and were recruited as volunteers. Athletes were students of the Department of Health and Sports Sciences and were also members of the volleyball club, basketball club, or track club (middle-distance runners) of the University. They had been training regularly for 2 years or longer before the study, $5 \mathrm{hr}$ a day, and 6 days a week, and participated regularly in competitive events in their respective sport specialties. Nonathletes were students of the Department of Food Sciences and Nutrition of the University and were not engaged in any regular sport activity. Subjects with clinically diagnosed acute or chronic inflammatory diseases, endocrine, cardiovascular, hepatic, renal diseases, hormonal contraception, and unusual dietary habits were excluded. Nobody reported to receive any medications or have regular supplements. The study was approved by the Ethics Committees of the University (No. 07-28) to be in accordance with the Helsinki declaration. All subjects gave written consent after the experimental procedure had been explained.

All participants underwent blood sampling after a 12-hr overnight fast, and measurements of anthropometric indices, body composition, blood pressure, and pulse rate as previously described. ${ }^{10,11}$ In fasted blood samples of 74 athletes and 210 nonathletes, the following were measured, ${ }^{10,11}$ plasma glucose, serum insulin, triglycerides (TG), cholesterol, high-density lipoprotein cholesterol (HDL-C), apolipoprotein AI (apoAI) and apolipoprotein B-100 (apoB), nonesterified fatty acid (NEFA), adiponectin, leptin, highsensitivity C-reactive protein (hsCRP), tumor necrosis factor$\alpha(\mathrm{TNF}-\alpha)$, and plasminogen activator inhibitor-1 (PAI-1).

Lean tissue mass, fat mass, and bone mineral mass for arms, legs, trunk, and the total body were measured using wholebody dual-energy X-ray absorptiometry (DXA) (Hologic QDR-2000, software version 7.20D, Waltham, MA) as previously reported. ${ }^{11}$ The ratio of trunk to leg fat was considered a marker of abdominal fat accumulation. ${ }^{13}$

A standard 75-grams oral glucose tolerance test (OGTT) was performed in 50 athletes and 118 nonathletes. Another set of 17 athletes and 18 nonathletes underwent a standardized meal test. This meal composed of a breakfast meal (total energy $450 \mathrm{kcal}$ ) and provided $33.3 \%$ of calories from fat (16.7 grams), 51.4\% from carbohydrates (57.8 grams), and $15.3 \%$ from protein (17.2 grams). The test meal contained more fat than a typical Japanese breakfast (20\%-25\%), but comparable energy content (median:
$423 \mathrm{kcal})$. OGTT and meal tests were performed during the morning after $12 \mathrm{hr}$ of fasting with blood samplings at baseline (0 min), 30, 60, and $120 \mathrm{~min}$ after the start of the drink/meal for the measurement of plasma glucose and serum insulin concentrations. Serum TG and NEFA were measured for meal tests as well. Participants were asked to consume the entire drink within $5 \mathrm{~min}$ and the entire meal within $15 \mathrm{~min}$. The area under the concentration curve (AUC) was calculated with the trapezoidal method.

The percentage of NEFA suppression was calculated as NEFA concentrations at 30,60, and 120 min divided by the fasting NEFA concentration in each participant. Homeostasis model assessment of insulin resistance (HOMA-IR) also was calculated as a more reflective surrogate of hepatic IR. ${ }^{14,15}$ Given the central role of obesity in the pathogenesis of IR, we calculated the ratio of serum leptin and adiponectin levels, which would reflect compromised adipose tissue function, including adipose-IR. ${ }^{16}$ The adipose-IR was calculated as a product of fasting insulin and NEFA concentrations. ${ }^{17}$

Data were presented as mean \pm standard deviation, unless otherwise stated. Due to deviation from normal distribution, inflammatory markers were logarithmically transformed for analysis. Comparisons between athletes and nonathletes were made with two-sample $t$-test. A two-tailed value of $P<0.05$ was considered significant. Statistics were performed with SPSS system 17.0 (SPSS, Inc., Chicago, IL).

\section{Results}

As previously reported, ${ }^{10-12}$ participants were normotensive and normal weight (Table 1). Collegiate athletes were characterized by higher lean mass and lower percentage of fat

Table 1. Blood Pressure and Anthropometric Features of Female Collegiate Athletes AND NONATHLETES

\begin{tabular}{lccc}
\hline & $\begin{array}{c}\text { Nonathletes } \\
(\mathrm{n}=311)\end{array}$ & $\begin{array}{c}\text { Athletes } \\
(\mathrm{n}=174)\end{array}$ & $\mathrm{P}$ \\
\hline Age (years) & $20.5 \pm 1.2$ & $19.9 \pm 1.3$ & 0.000 \\
Systolic BP (mmHg) & $106 \pm 10$ & $106 \pm 10$ & 0.830 \\
Diastolic BP (mmHg) & $61 \pm 8$ & $59 \pm 7$ & 0.001 \\
Resting pulse rate (bpm) & $65 \pm 10$ & $57 \pm 8$ & 0.000 \\
Height (cm) & $158.9 \pm 5.0$ & $165.2 \pm 6.1$ & 0.000 \\
Weight (kg) & $51.6 \pm 6.6$ & $59.1 \pm 6.6$ & 0.000 \\
BMI (kg/m $\left.{ }^{2}\right)$ & $20.4 \pm 2.2$ & $21.6 \pm 1.9$ & 0.000 \\
Waist circumference (cm) & $71.2 \pm 5.7$ & $74.8 \pm 5.0$ & 0.000 \\
Fat mass index $\left(\mathrm{kg} / \mathrm{m}^{2}\right)$ & $5.68 \pm 1.69$ & $5.02 \pm 1.51$ & 0.000 \\
Arm fat mass $(\mathrm{kg})$ & $1.2 \pm 0.6$ & $1.1 \pm 0.5$ & 0.045 \\
Leg fat mass $(\mathrm{kg})$ & $5.6 \pm 1.5$ & $5.5 \pm 1.6$ & 0.835 \\
Trunk fat mass $(\mathrm{kg})$ & $7.0 \pm 2.5$ & $6.5 \pm 2.1$ & 0.036 \\
Total fat mass $(\mathrm{kg})$ & $14.4 \pm 4.4$ & $13.7 \pm 4.1$ & 0.086 \\
Trunk/low body & $1.25 \pm 0.25$ & $1.17 \pm 0.21$ & 0.001 \\
Arm percentage fat $(\%)$ & $25.2 \pm 8.2$ & $19.3 \pm 7.2$ & 0.000 \\
Leg percentage fat $(\%)$ & $30.6 \pm 5.2$ & $25.3 \pm 5.0$ & 0.000 \\
Trunk percentage fat $(\%)$ & $28.6 \pm 6.6$ & $23.2 \pm 5.8$ & 0.000 \\
Total percentage fat $(\%)$ & $27.8 \pm 5.5$ & $22.8 \pm 5.1$ & 0.000 \\
Arm lean mass $(\mathrm{kg})$ & $3.2 \pm 0.4$ & $4.1 \pm 0.5$ & 0.000 \\
Leg lean mass $(\mathrm{kg})$ & $11.7 \pm 1.3$ & $15.2 \pm 1.8$ & 0.000 \\
Trunk lean mass $(\mathrm{kg})$ & $16.1 \pm 1.5$ & $20.2 \pm 2.0$ & 0.000 \\
Total lean mass $(\mathrm{kg})$ & $34.2 \pm 3.1$ & $42.9 \pm 4.3$ & 0.000 \\
\hline
\end{tabular}

Mean \pm SD.

$\mathrm{BMI}$, body mass index; $\mathrm{BP}$, blood pressure; SD, standard deviation. 
and resting pulse rate, although they had higher body mass index and waist circumference. Athletes had lower, although modest, arm and trunk fat mass, but comparable leg fat mass, and hence, lower trunk/leg fat ratio than nonathletes.

As compared with nonathletes, athletes had higher HDL$\mathrm{C}$ and apoAI and lower fasting NEFA and adipose-IR (Table 2). Athletes also had lower leptin, but comparable adiponectin levels, and hence lower leptin/adiponectin ratio. In addition, athletes had lower TNF- $\alpha$, but hsCRP and PAI-1 levels did not differ between the two groups. There was no difference in fasting insulin and HOMA-IR between athletes and nonathletes, although athletes had increased, although modestly, fasting glucose levels.

Both glucose and insulin concentrations at $120 \mathrm{~min}$ in OGTT were lower in athletes as compared with nonathletes (Table 3). Insulin AUC was lower in athletes as well, although the two groups did not differ in glucose AUC. Fasting glucose levels of athletes were higher, although modestly, in this subgroup analysis.

As shown in Fig 1, athletes had lower insulin concentrations at 60 and $120 \mathrm{~min}$ during a meal test and hence lower insulin AUC (Table 4). The groups did not differ in postmeal glycemia, NEFA levels at any time point, and percentage NEFA suppression during the meal test (Fig. 1), as well as AUC of glucose, NEFA, and TG (Table 4). Again, fasting glucose levels of athletes were higher, although modestly, as compared with nonathletes (Fig. 1).

\section{Discussion}

The main finding of this study is that even in healthy, normal-weight Japanese women in early adult life, athletes,

Table 2. Biochemical Characteristics of Nonathletes and Athletes

\begin{tabular}{lccc}
\hline & $\begin{array}{c}\text { Nonathletes } \\
(\mathrm{n}=311)\end{array}$ & $\begin{array}{c}\text { Athletes } \\
(\mathrm{n}=174)\end{array}$ & $\mathrm{P}$ \\
\hline Fasting glucose $(\mathrm{mg} / \mathrm{dL})$ & $83 \pm 7$ & $86 \pm 6$ & 0.000 \\
Fasting insulin $(\mu \mathrm{U} / \mathrm{mL})$ & $6.2 \pm 3.4$ & $5.8 \pm 4.6$ & 0.296 \\
HbA1c $(\%)$ & $5.2 \pm 0.6$ & $5.2 \pm 0.5$ & 0.152 \\
HOMA-IR & $1.27 \pm 0.87$ & $1.26 \pm 1.44$ & 0.920 \\
Adipose-IR & $3.45 \pm 2.73$ & $2.11 \pm 1.36$ & 0.000 \\
Cholesterol $(\mathrm{mg} / \mathrm{dL})^{\text {Triglycerides }(\mathrm{mg} / \mathrm{dL})}$ & $182 \pm 28$ & $181 \pm 26$ & 0.681 \\
HDL-C $(\mathrm{mg} / \mathrm{dL})$ & $75 \pm 34$ & $56 \pm 21$ & 0.425 \\
LDL-C $(\mathrm{mg} / \mathrm{dL})$ & $96 \pm 13$ & $77 \pm 13$ & 0.025 \\
Apolipoprotein AI (mg/dL) & $164 \pm 20$ & $172 \pm 21$ & 0.111 \\
Apolipoprotein B (mg/dL) & $70 \pm 15$ & $69 \pm 13$ & 0.000 \\
NEFA $(\mathrm{mEq} / \mathrm{L})$ & $0.56 \pm 0.22$ & $0.41 \pm 0.18$ & 0.000 \\
Leptin $(\mathrm{ng} / \mathrm{mL})$ & $8.6 \pm 3.9$ & $6.4 \pm 2.9$ & 0.000 \\
Adiponectin $(\mu \mathrm{g} / \mathrm{mL})$ & $11.5 \pm 4.3$ & $11.6 \pm 4.3$ & 0.879 \\
Leptin/adiponectin ratio & $0.93 \pm 0.93$ & $0.64 \pm 0.40$ & 0.000 \\
PAI-1 $(\mathrm{ng} / \mathrm{mL})$ & $21 \pm 13$ & $21 \pm 11$ & 0.981 \\
TNF- $\alpha(\mathrm{pg} / \mathrm{mL})$ & $0.68 \pm 0.48$ & $0.58 \pm 0.37$ & 0.018 \\
hsCRP $(\mu \mathrm{g} / \mathrm{dL})$ & $29 \pm 69$ & $33 \pm 79$ & 0.542 \\
\hline
\end{tabular}

Mean \pm SD.

${ }^{a}$ Two hundred ten nonathletes and seventy-four athletes.

HbAlc, glycated hemoglobin; HDL-C, high-density lipoprotein cholesterol; HOMA, homeostasis model assessment; hsCRP, highsensitivity C-reactive protein; IR, insulin resistance; LDL-C, lowdensity lipoprotein cholesterol; NEFA, nonesterified fatty acids; PAI-1, plasminogen activator inhibitor- 1 ; TNF- $\alpha$, tumor necrosis factor- $\alpha$.
Table 3. Oral Glucose Tolerance Tests IN ATHLETES AND Nonathletes

\begin{tabular}{lccc}
\hline & $\begin{array}{c}\text { Nonathletes } \\
(\mathrm{n}=118)\end{array}$ & $\begin{array}{c}\text { Athletes } \\
(\mathrm{n}=50)\end{array}$ & $\mathrm{P}$ \\
\hline Glucose $(\mathrm{mg} / \mathrm{dL})$ & & & \\
$0 \mathrm{~min}$ & $82 \pm 6$ & $87 \pm 6$ & 0.000 \\
$30 \mathrm{~min}$ & $122 \pm 23$ & $125 \pm 29$ & 0.467 \\
$60 \mathrm{~min}$ & $104 \pm 33$ & $99 \pm 29$ & 0.337 \\
$120 \mathrm{~min}$ & $94 \pm 23$ & $85 \pm 13$ & 0.001 \\
Insulin $(\mu \mathrm{U} / \mathrm{mL})$ & & & \\
0 min & $5.5 \pm 2.8$ & $6.6 \pm 3.6$ & 0.029 \\
$30 \mathrm{~min}$ & $54 \pm 34$ & $54 \pm 25$ & 0.997 \\
$60 \mathrm{~min}$ & $44 \pm 27$ & $38 \pm 17$ & 0.098 \\
$120 \mathrm{~min}$ & $42 \pm 25$ & $23 \pm 14$ & 0.000 \\
Glucose-AUC $(\mathrm{mg} / \mathrm{dL} .2 \mathrm{hr})$ & $207 \pm 42$ & $201 \pm 38$ & 0.399 \\
Insulin-AUC $(\mu \mathrm{U} / \mathrm{mL} .2 \mathrm{hr})$ & $82 \pm 39$ & $69 \pm 25$ & 0.010
\end{tabular}

Mean \pm SD.

AUC, area under the concentration curve.

as compared with nonathletes, had not only lower adipose-IR, a marker of adipose-IR, ${ }^{17}$ but also lower leptin/adiponectin ratio, which would reflect compromised adipose tissue function, including adipose-IR. ${ }^{16}$ In addition, endurance training was associated with comparable NEFA suppression in the presence of lower postmeal insulinemia, suggesting increased adipose insulin sensitivity. The present study confirms the previous observation that endurance training was associated with increased muscle insulin sensitivity in nonobese, young women ${ }^{18}$ and extends to the fact that serum adiponectin did not change, despite increased muscle and adipose insulin sensitivity. It is noteworthy that these findings were observed in a young, normal-weight population, in which confounding factors are so scarce. ${ }^{10-12}$ Increased adipose and muscle insulin sensitivity in our athletes may be related, in part, to lower trunk/leg fat ratio, a good marker of abdominal or central adiposity, ${ }^{13}$ and higher lean mass, respectively.

The effect of insulin on postprandial NEFA metabolism is complex. In adipose tissue, insulin stimulates intravascular TG lipolysis (lipoprotein lipase-mediated lipolysis of TG of TG-rich lipoproteins in the circulation) ${ }^{19}$ and suppresses intracellular adipose tissue lipolysis. ${ }^{20}$ Insulin may contribute to adipose tissue uptake of NEFAs generated from intravascular TG lipolysis, ${ }^{20,21}$ that is, insulin may reduce NEFA spillover. Direct adipose tissue uptake of NEFA was recently demonstrated in vivo in humans. ${ }^{22,23}$ It has also been reported that the net spillover of NEFA came from adipose tissue, but not from muscle, in the postprandial state in healthy humans, ${ }^{22,24}$ suggesting that the most important source of NEFA spillover is adipose tissue. Taken together, comparable NEFA suppression in the presence of lower postmeal insulinemia found in athletes in the present study may be net results of the complex dynamics of NEFA metabolism described above and suggest that endurance training is associated with increased insulin sensitivity in adipose tissue in young women, which was supported by lower adipose-IR and leptin/adiponectin ratio in female athletes.

Although exercise training increases insulin-mediated glucose uptake in the whole body, ${ }^{25,26}$ adaptations in skeletal muscle are considered central to this effect because this 

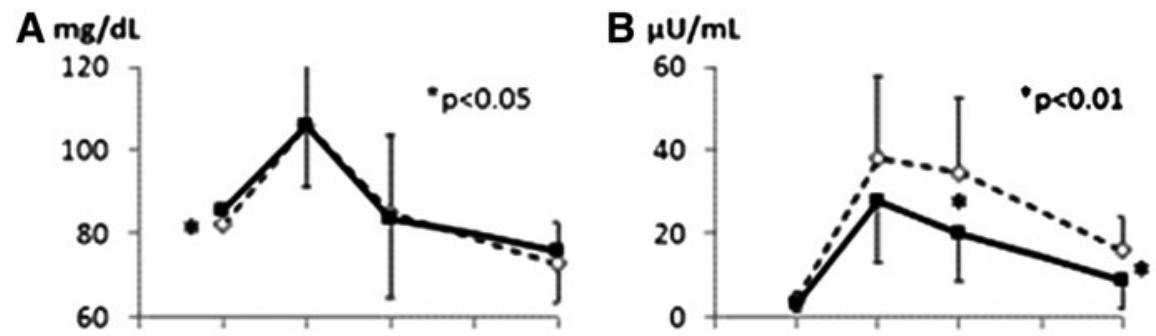

FIG. 1. Changes in glucose (A), insulin (B), NEFA (C), and percentage NEFA suppression (D) during a standardized meal test in athletes (solid lines) and nonathletes (dotted lines). The percentage of
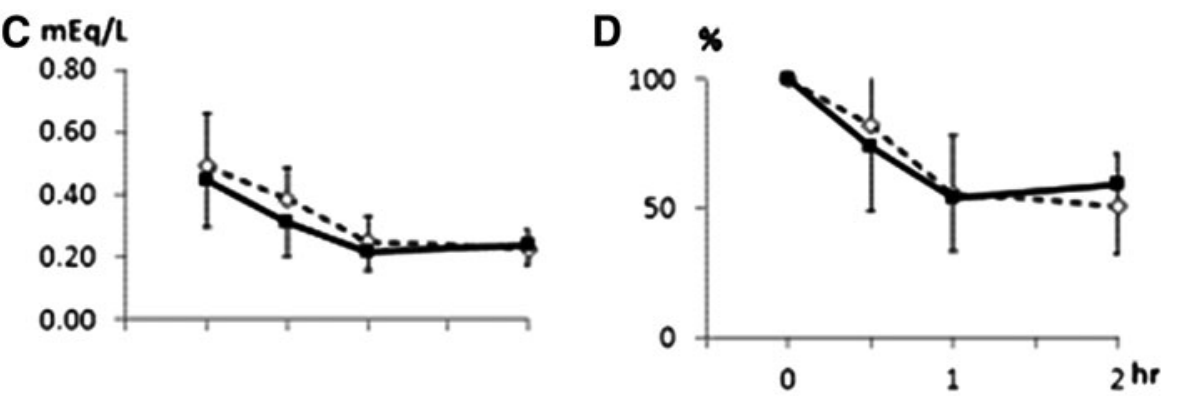
NEFA suppression was calculated as NEFA concentrations at 30, 60, and $120 \mathrm{~min}$ divided by the fasting NEFA concentration in each participant. Data are mean \pm SD. $* P<0.01$ between athletes and nonathletes. NEFA, nonesterified fatty acids.

tissue is responsible for the majority of glucose disposal. ${ }^{27}$ As previously reported ${ }^{18,25}$ and confirmed in the present study, endurance training is associated with increased muscle insulin sensitivity even in young, normal-weight women. Increased insulin sensitivity in skeletal muscle was supported by lower concentrations of 2-hr glucose and insulin in OGTT in athletes, both of which were a crude marker of insulinmediated glucose disposal in skeletal muscle, that is, muscle insulin sensitivity. ${ }^{28,29}$

Circulating leptin is correlated to changes in adiposity, and exercise training-induced decreases in adiposity result in decreased circulating leptin in both rodents and humans, as recently reviewed ${ }^{24,30}$ and confirmed in the present study. However, studies in both rodent models and humans have not come to a consensus on the effects of exercise on adiponectin concentrations. $^{24,30}$ No difference in serum adiponectin between athletes and nonathletes in the present study may be in line with observations ${ }^{31-33}$ that in obese subjects there was no change in plasma adiponectin concentration with exercise training that did not alter body mass, despite an improvement in insulin action. In contrast, plasma adiponectin increased in conjunction with insulin action after weight loss. ${ }^{31}$ It is reported that weight loss larger than $10 \%$ was necessary to obtain a continuous significant increase in plasma adiponectin levels in obese subjects. ${ }^{34}$

It has been reported that elevated inflammatory markers are decreased by exercise training in patients with CVD or cardiovascular risk factors ${ }^{9}$ and in obese individuals. ${ }^{30}$ In

Table 4. The Area Under the Concentration Curve During a Standardized Meal Test in Athletes and Nonathletes

\begin{tabular}{lccc}
\hline & $\begin{array}{c}\text { Nonathletes } \\
(\mathrm{n}=18)\end{array}$ & $\begin{array}{c}\text { Athletes } \\
(\mathrm{n}=17)\end{array}$ & $\mathrm{P}$ \\
\hline Glucose-AUC (mg/dL. 2 hr) & $174 \pm 20$ & $175 \pm 21$ & 0.852 \\
Insulin-AUC ( $\mu \mathrm{U} / \mathrm{mL} .2 \mathrm{hr})$ & $54.2 \pm 24.4$ & $34.1 \pm 17.4$ & 0.009 \\
TG-AUC $(\mathrm{mg} / \mathrm{dL} .2 \mathrm{hr})$ & $141 \pm 49$ & $137 \pm 46$ & 0.805 \\
NEFA-AUC $(\mathrm{mEq} / \mathrm{L} .2 \mathrm{hr})$ & $0.62 \pm 0.13$ & $0.55 \pm 0.13$ & 0.128 \\
\hline
\end{tabular}

the present study, young nontrained women were normal weight and hence, had serum concentrations of inflammatory markers that were not elevated. Therefore, it may be reasonable to assume that inflammatory markers were not reduced by endurance training, except for modest decrease in TNF- $\alpha$ in athletes. There is no clear consensus regarding the effects of training on TNF- $\alpha$ in blood and adipose tissue. ${ }^{30}$ In a study in young normal-weight adults, 12 weeks of endurance training actually increased the blood concentration of TNF- $\alpha .{ }^{35}$

HOMA-IR, a marker of hepatic IR, ${ }^{14,15,36}$ in athletes was equal to or rather higher than that in nonathletes in the present study. This is mainly due to consistent increases, although modest, in fasting glucose in athletes. We have no appropriate explanation for this. Endurance training in rats increased the hepatic glycogen content, ${ }^{37}$ which has been shown to be directly related to hepatic glucose production. ${ }^{38}$ Following an overnight fast, $50 \%-75 \%$ of hepatic glucose production was provided by glycogenolysis. ${ }^{39}$ Therefore, we speculate that increased fasting glucose in athletes in the present study may be due, at least in part, to an elevated hepatic glycogen content in trained compared with untrained subjects.

This study has several strengths, including homogeneous study population with scarce confounding factors, and accurate and reliable measures of body composition by DXA. The main limitation of our study is that DXA does not allow separate quantification of intermuscular and subcutaneous fat in the legs and visceral fat and subcutaneous fat in the trunk. ${ }^{11}$ However, fat mass in the legs in our study may be mainly the subcutaneous fat depot. ${ }^{11}$ The cross-sectional design of the present study complicates the drawing of causal inferences, and a single measurement of biochemical variables may be susceptible to short-term variation, which would bias the results toward the null. We used crude measures of insulin sensitivity in muscle and adipose tissue, which may be less accurate. Finally, statistical power was not calculated.

In conclusion, endurance training was associated with increased insulin sensitivity in adipose tissue as well as 
skeletal muscle without changes in circulating adiponectin in young, normal-weight Japanese women.

\section{Acknowledgment}

The authors are indebted to all the participants for their dedicated and conscientious collaboration.

\section{Author Disclosure Statement}

No competing financial interests exist.

\section{References}

1. Ford ES, Li C, Zhao G, et al. Trends in the prevalence of low risk factor burden for cardiovascular disease among United States adults. Circulation 2009;120:1181-1188.

2. Chen Y, Copeland WK, Vedanthan R, et al. Association between body mass index and cardiovascular disease mortality in East Asians and South Asians: Pooled analysis of prospective data from the Asia Cohort Consortium. BMJ 2013;347:f5446.

3. Arkan MC, Hevener AL, Greten FR, et al. IKK-beta links inflammation to obesity-induced insulin resistance. Nat Med 2005;11:191-198.

4. Weisberg SP, McCann D, Desai M, et al. Obesity is associated with macrophage accumulation in adipose tissue. J Clin Invest 2003;112:1796-1808.

5. Furukawa S, Fujita T, Shimabukuro M, et al. Increased oxidative stress in obesity and its impact on metabolic syndrome. J Clin Invest 2004;114:1752-1761.

6. de Ferranti S, Mozaffarian D. The perfect storm: Obesity, adipocyte dysfunction, and metabolic consequences. Clin Chem 2008;54:945-955.

7. Pattyn N, Cornelissen VA, Eshghi SR, et al. The effect of exercise on the cardiovascular risk factors constituting the metabolic syndrome: A meta-analysis of controlled trials. Sports Med 2013;43:121-133.

8. Palmefors H, DuttaRoy S, Rundqvist B, et al. The effect of physical activity or exercise on key biomarkers in atherosclerosis-a systematic review. Atherosclerosis 2014;235: 150-161.

9. Conn VS, Koopman RJ, Ruppar TM, et al. Insulin sensitivity following exercise interventions: Systematic review and meta-analysis of outcomes among healthy adults. J Prim Care Community Health 2014;5:211-222.

10. Tanaka M, Yoshida T, Bin W, et al. FTO, abdominal adiposity, fasting hyperglycemia associated with elevated HbA1c in Japanese middle-aged women. J Atheroscler Thromb 2012;19:633-642.

11. Tanaka S, Wu B, Honda M, et al. Associations of lower-body fat mass with favorable profile of lipoproteins and adipokines in healthy, slim women in early adulthood. J Atheroscler Thromb 2011;18:365-372.

12. Terazawa-Watanabe M, Tsuboi A, Fukuo K, et al. Association of adiponectin with serum preheparin lipoprotein lipase mass in women independent of fat mass and distribution, insulin resistance, and inflammation. Metab Syndr Relat Disord 2014;12:416-421.

13. Lim U, Turner SD, Franke AA, et al. Predicting total, abdominal, visceral and hepatic adiposity with circulating biomarkers in Caucasian and Japanese American women. PLoS One 2012; 7:e43502.

14. Matthews DR, Hosker JP, Rudenski AS, et al. Homeostasis model assessment: Insulin resistance and beta-cell function from fasting plasma glucose and insulin concentrations in man. Diabetologia 1985;28:412-419.

15. Abdul-Ghani MA, Jenkinson CP, Richardson DK, et al. Insulin secretion and action in subjects with impaired fasting glucose and impaired glucose tolerance: Results from the Veterans Administration Genetic Epidemiology Study. Diabetes 2006;55:1430-1435.

16. Finucane FM, Luan J, Wareham NJ, et al. Correlation of the leptin:adiponectin ratio with measures of insulin resistance in nondiabetic individuals. Diabetologia 2009;52: 2345-2349.

17. Malin SK, Kashyap SR, Hammel J, et al. Adjusting glucose-stimulated insulin secretion for adipose insulin resistance: An index of beta-cell function in obese adults. Diabetes Care 2014;37:2940-2946.

18. Poehlman ET, Dvorak RV, DeNino WF, et al. Effects of resistance training and endurance training on insulin sensitivity in nonobese, young women: A controlled randomized trial. J Clin Endocrinol Metab 2000;85:2463-2468.

19. Fielding BA, Frayn KN. Lipoprotein lipase and the disposition of dietary fatty acids. Br J Nutr 1998;80:495-502.

20. Miles JM, Wooldridge D, Grellner WJ, et al. Nocturnal and postprandial free fatty acid kinetics in normal and type 2 diabetic subjects: Effects of insulin sensitization therapy. Diabetes 2003;52:675-681.

21. Evans K, Clark ML, Frayn KN. Effects of an oral and intravenous fat load on adipose tissue and forearm lipid metabolism. Am J Physiol 1999;276(2 Pt 1):E241-E248.

22. Bickerton AS, Roberts R, Fielding BA, et al. Preferential uptake of dietary fatty acids in adipose tissue and muscle in the postprandial period. Diabetes 2007;56:168-176.

23. Shadid S, Koutsari C, Jensen MD. Direct free fatty acid uptake into human adipocytes in vivo: Relation to body fat distribution. Diabetes 2007;56:1369-1375.

24. Stanford KI, Middelbeek RJ, Goodyear LJ. Exercise effects on white adipose tissue: Beiging and metabolic adaptations. Diabetes 2015;64:2361-2368.

25. Rodnick KJ, Haskell WL, Swislocki AL, et al. Improved insulin action in muscle, liver, and adipose tissue in physically trained human subjects. Am J Physiol 1987;253(5 Pt 1): E489-E495.

26. Stallknecht B, Larsen JJ, Mikines KJ, et al. Effect of training on insulin sensitivity of glucose uptake and lipolysis in human adipose tissue. Am J Physiol Endocrinol Metab 2000;279:E376-E385.

27. Bonadonna RC, Saccomani MP, Seely L, et al. Glucose transport in human skeletal muscle. The in vivo response to insulin. Diabetes 1993;42:191-198.

28. Winner D, Norton L, Kanat M, et al. Strong association between insulin-mediated glucose uptake and the 2-hour, not the fasting plasma glucose concentration, in the normal glucose tolerance range. J Clin Endocrinol Metab 2014; 99:3444-3449.

29. Stumvoll M, Mitrakou A, Pimenta W, et al. Use of the oral glucose tolerance test to assess insulin release and insulin sensitivity. Diabetes Care 2000;23:295-301.

30. Sakurai T, Ogasawara J, Kizaki T, et al. The effects of exercise training on obesity-induced dysregulated expression of adipokines in white adipose tissue. Int $J$ Endocrinol 2013;2013:801743.

31. Hulver MW, Zheng D, Tanner CJ, et al. Adiponectin is not altered with exercise training despite enhanced insulin action. Am J Physiol Endocrinol Metab 2002;283:E861$\mathrm{E} 865$. 
32. Abbasi F, Lamendola $\mathrm{C}$, McLaughlin $\mathrm{T}$, et al. Plasma adiponectin concentrations do not increase in association with moderate weight loss in insulin-resistant, obese women. Metabolism 2004;53:280-283.

33. Nassis GP, Papantakou K, Skenderi K, et al. Aerobic exercise training improves insulin sensitivity without changes in body weight, body fat, adiponectin, and inflammatory markers in overweight and obese girls. Metabolism 2005;54: 1472-1479.

34. Madsen EL, Rissanen A, Bruun JM, et al. Weight loss larger than $10 \%$ is needed for general improvement of levels of circulating adiponectin and markers of inflammation in obese subjects: A 3-year weight loss study. Eur J Endocrinol 2008;158:179-187.

35. Horne L, Bell G, Fisher B, et al. Interaction between cortisol and tumour necrosis factor with concurrent resistance and endurance training. Clin J Sport Med 1997;7:247-251.

36. Tripathy D, Almgren P, Tuomi T, et al. Contribution of insulin-stimulated glucose uptake and basal hepatic insulin sensitivity to surrogate measures of insulin sensitivity. Diabetes Care 2004;27:2204-2210.
37. Cunha TS, Tanno AP, Costa Sampaio Moura MJ, et al. Influence of high-intensity exercise training and anabolic androgenic steroid treatment on rat tissue glycogen content. Life Sci 2005;77:1030-1043.

38. Vissing J, Wallace JL, Galbo H. Effect of liver glycogen content on glucose production in running rats. $J$ Appl Physiol (1985) 1989;66:318-322.

39. Drouin R, Lavoie C, Bourque J, et al. Increased hepatic glucose production response to glucagon in trained subjects. Am J Physiol 1998;274(1 Pt 1):E23-E28.

Address correspondence to:

Tsutomu Kazumi, MD, PhD Research Institute for Nutrition Sciences Mukogawa Women's University 6-46, Ikebiraki-cho Nishinomiya 663-8558

Japan

E-mail: kazumi@mukogawa-u.ac.jp 